able symptom much aggravated, and a vomiting of fæces every ten minutes. Again the taxis, employed with much gentleness, failed to reduce the strangulated intestine, and an operation was proposed to her, but resolutely refused, although all chances of life to her without it were so hopeless. An expedient now occurred to my recollection, which I had some years before resorted to, in a similar emergency, with success, in the case of an old seaman during a royage to the East, who had objected, with the like obstinacy, to a surgical operation, and appeared to be as near the brink of eternity as the present sufferer. I therefore resolved upon the measure as a forlorn hope. I procur d a large vessel of water, which was of ice temperature, from the inclemency of the seàson, and with Reid's enema apparatus commenced throwing the freezing fluid up the rectum for several minutes duration, and to the amount of about two quarts. This gave an instantaneous rally to the whole system, and while under this apparent re-action, I again resorted to manipulation, by bringing her knees and body, with the shoulders, towards the pelvis; then grasping the tumour with the fingers of both hands, in place of pushing the contents up towards the abdominal ring, I gently pulled them down, which was easily effected, as the abdominal parietes, since the cold water injection, seemed to have become suddenly relaxed. With a little steady, gentle compression, I speedily forced out the air of the intestine, and then, to my great satisfac. tion, it became forth with extricated from its strangulated state, and returned, with the whole contents of the hernial sac, into its proper situation. 'In a few hours alvine evacuations came away copiously, by their natural exit, although the inflammatory symptoms, nausea and tenderness of the abdomen, did not altogether subside for several days; but under the antiphlogistic treatment, and watchful care, her recovery, subsequently, was rapid. In the course of ten days she was enabled to resume her domestic avocations, and is now enjoying excellent health.

Whether the case would have been brought to a similar termination if she had submitted to an operation, semains questionable. At all events, she was spared that pain; and, certainly, had the period of her sufferings much shortened during convalescence.

The above remedy has this important advantage, that it can at all times be employed with facility, and without, I apprehend, any probability of the serious consequences of cutting down upon such vital parts as the peritoneal coat and intestines., I do not recollect to have seen it recommended by any of our great modern writers, although it has been found effective in an analogous malady, intussusception. Its modus ope-. randi may, perhaps, be thus accounted for: -When a portion of bowel has been long confined by a stricture, the great distention of the abdominal parietes usually observed, indicates a copious extrication of air and elastic vapour, which the cold water must condense, at the same time that it acts as an antispasmodic, exciting a natural peristaltic action, and relaxing the abdominal iliac and psoas muscles, and thereby extricating the constricted gut; or, mechanically, by its weight, the water may overcome the obstruction which refused to yield to the more common measures.

\section{THE ERGOT OF RYE in THE}

\section{SECONDARY HAMORRHAGE OF LABOUR.}

\section{To the Editor of THE LANCET.}

Sir:-The following case is forwarded for publication in your very able and scientific Journal. I am, Sir, your obedient servant,

Christ. Bradley, M.R.C.S.L., \&C. Church, near Blackburn, Lancashire. April 8th, 1837.

On the morning of the 27th of March last, at about half-past five o'clock, I was called to attend Mrs. B., who was in labour with her third child. The pains commenced at about three o'clock on the same morning, but were not strong. On examination, I found the os uteri fully dilated, the membranes protruding, and the head presenting. I immediately ruptured the membranes. The pains increased in strength and frequency, and in half an hour after my arrival the child was born. Previous to the birth of the cliild, Mrs. B. told me that she had floodcd a little after the birth of her other children. The enlargement of the abdomen being considerahly greater in this than in her former pregnancies, I had the more reason to apprehend flooding after this also. I placed the hand of the nurse upon the abdomen of the mother, over the fundus of the uterus, and desired her to make a firm pressure there at the moment the child was born, which was carefully attended to. At the moment the child was born there issued a large gush of blood. The nurse kept up the pressure, the womb contracted, the hæmorrrhage ceased, and, in about five minutes afterwards, the placenta, along with several large clots of blood, was expelled by the efforts of the uterus alone. The nurse removed her hand, and I applied a compress and bandage over the uterine region, and left the mother to attend to the child. On returning to the bedside, I found my patient blanched and sickly; the pulse scarcely perceptible; the eyes semiclosed 
and glassy; frequent sighing. I immediately examined the cloth which had been applied; it was very little soiled with discharge, and there was none escaping into the bed. I thẹn placed my hand upon the abdomen, and found that the uterus was two-thirds the size that it had been before delivery. The cause of the blanched state, \&c., of my patient was now cle arly manifest, and there was not a moment of time to be lost; I therefore immediately passed my hand into the uterus, and found the vagina and cervix uteri full of clots, but the blood within the uterus was principally fluid. I pressed my knuckles gently against the sides and fundus of the uterus, the nurse resuming the pressure from without, as before. The womb began to contract, and expelled my hand, together with some clots of blood. My patient now fainted very completely; but by keeping the head low, admitting cold air into the room, giving a little aromatic spirit of ammonia, and applying volatile salts to the nose, she rallied, and the hæmorrhage abated for a short time. In about ten minutes the uterus began to rise again, and felt soft and flabby; and when the nurse pressed upon the uterus the blood flowed freely out of the vagina again. I applied cold vinegar and water cloths to the region of the uterus. My patient fainted, and I expected that every moment would terminate her earthly existence; however, by the use of the means before-mentioned, she again rallied. The blood continued to flow, but in a mitigated degree. I then desired the nurse to remove her hand, and allow me to place mine there, for the purpose of rubbing my fingers frequently over the uterus, but it appeared to be all of no avail. The nurse re-applied her hand, as before, whilst I prepared, as quickly as possible, a decoction of the ergot of rye, having seen it recommended for secondary hæmorrhage in the pages of your valuable Journal. I gave her half a drachm of the ergot, boiled, during ten minutes, in six onnces of water. This brought on contraction of the uterus. In about eight minutes after it was taken, several clots were expelled, and the uterus gradually became firmer, and settled lower and lower, until $I$ could only just perceive the fundus over the pubis. The hæmorrhage ceased just in time to prevent the fatal catastrophe which must otherwise inevitably have taken place in a few minutes. I then tightened the bandage, and applied the compress, and the patient has since done well.

In those cases in which we expect secondary hæmorrhage, might we not, by giving the secale cornutum immediately before the birth of the child, prevent it altogether?

\section{DIVISION OF THE VAGINA INTO TWO PARTS.}

\section{To the Editor of THE IaAcer.}

SIR :-On Tuesday night, the 29th November, 1836, I was required to go into the country to attend Mrs. E. B., who was in labour with her first child. On inquiry I found that labour had commenced on the Saturday evening previous. The pains, at first violent, had remitted for a time. On Monday evening they became very severe, and during that night the membranes broke. The pains again ceased ; on Tuesday afternoon they came on very violently, and I was then sent for. I arrived at about 9 o'clock, P. M. I found the patient extended on the floor on her back, with her hips on a small straw mattress, and her shoulders supported on the back of a chair. That is the usual, in. convenient, and disgusting method of being "putto-bed,"amongst the lower ranks in this country. The pains were strong, and without intermission. After an examination, which, from the awkward position, was not satisfactory, I had her immediately conveyed to-bed; I there renewed my examination. The external parts were sufficiently lubricated with mucus, though, apparently, not yet sufficiently dilated. The vertex of the child presented. The constant contrac. tion of the uterus prevented me from passing my finger up to the ear, to discover more minutely the nature of the presentation; the state of the parts, however, excited in my mind a snspicion of impaction, with malposition of the head. The pains, although constant, had become lessened in degree. I judged it, therefore, to be expedient to administer a dose of the ergot of rye, which was repeated four times, at intervals of from a quarter to half an hour. This had the effect of increasing the uterine contraction, though, unhappily, without advancing the labour. Fearing that the powers of life would sink under this continued and acute suffering, her pulse having already begun to waver, and become weak, I administered a dose of tincture of opium and spirit of ammonia. The dose was repeated at short intervals, until 180 drops of the tincture had been taken, and it was not until then that any apparent relief was obtained, and that was so slight, and the symptoms were so very urgent-finding, also, that the case admitted of no delay, my patient having, by this time, become amaurotic and delirious, that I determined to attempt the delivery by the forceps. Haring previously emptied the bladder of a considerable quantity of urine with the catheter, I introduced the forefinger of my left hand, for the purpose of guiding the left blarle of the forceps. I" found, that while on the right side $I$ could extend my 